\title{
CORRECTION
}

\section{Correction: Altered network connectivity predicts response to cognitive-behavioral therapy in pediatric obsessive-compulsive disorder}

Marilyn Cyr ID, David Pagliaccio, Paula Yanes-Lukin, Martine Fontaine, Moira A. Rynn and Rachel Marsh

Neuropsychopharmacology (2020) 45:1241; https://doi.org/10.1038/s41386-020-0647-6

Correction to: Neuropsychopharmacology https://doi.org/10.1038/ s41386-020-0613-3, published online 17 January 2020

The original version of this Article omitted the following from the Funding and Disclosure section:
Dr. Moira Rynn receives an honorarium as a DSMB member from Allergan Inc.

This has now been corrected in both the PDF and HTML versions of the Article. 